\title{
CIRCULATION OF PESTICIDES IN THE BIOSPHERE
}

\author{
L. I. MEDVED \\ All-Union Scientific-Research Institute of Hygiene and Toxicology of \\ Pesticides, Polymers and Plastics, Kiev, USSR
}

\begin{abstract}
In the USSR emphasis is focused on studying pesticide circulation in the environment, especially to determine the regularities of their migration and accumulation in living beings. Over 500 laboratories for systematically estimating pesticide residues in plant and animal products, water, drinking watersupplies, atmospheric air and working area air are established at the National Sanitary and Epidemiology Stations. Summarizing research results permits us to elicit the main reasons for excessive pesticide pollution of separate environmental units and work out scientific standards for each pesticide use. Establishment of time-keeping between the last pesticide application and harvest of the crop is of particular interest. These measures prevent appearance of intolerable pesticide residues in foods. The best time for the next work after pesticide application in fields, gardens, etc. is controlled. Sanitary standards for distance between target and populated areas have been established. The capacity of pesticide storage in food chains is determined. The main pesticide cumulator is soil from which chemicals transfer through root systems into plants. Heptachlor is found in carrot in concentrations of $1 \mathrm{mg} / \mathrm{kg}$ at a level of some thousandths of milligrammes in the soil. Pesticides are migrating from soil to underground water, natural water and atmospheric air. A secondary pollution risk is possible. Concentrations of some thousandths of $\mathrm{mg} / 1$ in water, some hundredths and tenths of $\mathrm{mg} / \mathrm{kg}$ in zoophytoplankton, about $5 \mathrm{mg} / \mathrm{kg}$ in fish have been detected. Pesticide concentrations of $1-2 \mathrm{mg} / \mathrm{kg}$ of body weight in hare, $5-8 \mathrm{mg} / \mathrm{kg}$ in wolf have been identified. Only a proportion of such chemicals is placed on target areas. The rest of the aerosol is carried away by the wind over a distance to higher atmospheric layers resulting in precipitations. To prevent danger it is necessary to select pesticides strictly precluding any prolonged persistent and stable preparations.
\end{abstract}

It is difficult to mention a problem of more urgent concern for contemporary society than the problem of protection of the environment from chemical pollutants. The wellbeing of today's and future generations depends to a large degree on the solution of this problem.

Various chemical substances are found in all the components of the biosphere and, constantly circulating, they migrate from one part of the biosphere to another. Many chemical substances are able to accumulate in living beings; they have been detected in plants, in man and in animal 


\section{I. MEDVED}

organisms. The rate of evironmental contamination with chemical substances in various regions of the world varies widely. It depends upon the level of industrial development in the various countries and upon the governmental preventative measures against pollution of the atmospheric air of cities and towns, of open water reservoirs, of food, soil, etc.

The attention of many scientists is increasingly drawn to the problem of the protection of the environment. In many countries governmental organizations and scientific centres have been created, and international cooperation is widening. The USSR and the USA entered into a treaty of cooperation on the problem of environmental protection and they are carrying out joint researches.

This problem of environmental protection is rather complex and manysided involving many particular problems, such as the influence of the circulation of pesticides in the biosphere on living creatures and on the health of the population.

Considering the problem of environment protection from chemical contamination one should distinguish: (1) preventable, (2) temporarily unpreventable and (3) unpreventable contamination.

Preventable contamination is the contamination of atmospheric air and reservoirs by industrial enterprises. Effective gas and dust separators, purificatory constructions and other equipment may give positive results. This problem requires constant attention and causes great expense. The present level of the development of science and technology guarantees the possibility of the prediction of environmental contamination from industrial enterprises.

Temporarily unpreventable chemical contamination is derived from exhaust gases from traffic, primarily from automobiles. Already today it is impossible to breathe adequately in cities with millions of automobiles. In many countries scientists and engineers are working on the creation of electrically powered vehicles and technical arrangements for the absorption of exhaust gases. Such arrangements are likely to be finalized and the principal source of atmospheric air pollution in cities will be stamped out in the foreseeable future.

Practically unpreventable today and probably in the foreseeable future is the contamination of the biosphere with pesticides. To protect crops from pests and diseases, people purposely load chemical substances in planes, tractors, hand and machine sprayers and dusters to treat hundreds of millions of hectares of fields, forests, gardens and other agricultural lands. Under aerial treatment only 50-60 per cent of chemicals get to the target areas and the rest migrates to the higher layers of the atmosphere and is transferred over long distances by the wind.

Pesticides are created and used for killing specific organisms. Having high biological activity they may harm not only the target beings, but some other organisms as well. Therefore they are potentially hazardous for living creatures and the health of the people. Pesticides can produce in man acute, subacute or chronic intoxications and some of them possess carcinogenic, mutagenic, embryotoxic, allergenic and other adverse properties.

One of the prominent scientists, academician V. I. Vernadsky ${ }^{1}$ created a theory of the biosphere, all the components of which are interrelated and 
interdependent, though we usually consider each of them independently. One can observe such an interrelation while studying the problem of the circulation of pesticides in the biosphere.

\section{ATMOSPHERIC AIR}

The first component of the biosphere where pesticides are released during the treatment of plants is atmospheric air. Through atmospheric air the chemicals pass to the target plants and soil, but some of them are carried away by the wind horizontally and vertically for different distances.

There is a multifactor relationship of the concentration of pesticides in atmospheric air and the distance of their distribution depending upon the methods and the modes of treatment, on the form of formulation, on microclimatic conditions, etc. Thus, the mean daily concentration of methylmercaptophos in Uzbekistan was $0.33 \mathrm{mg} / \mathrm{m}^{3}$ after aerial spraying and 0.07 $0.16 \mathrm{mg} / \mathrm{m}^{3}$ after tractor-borne pneumatic spraying. Following the ground dusting of cotton in Azerbaijan, the contamination of atmospheric air was four or five times less than after an aerial application. In the Uzbek SSR in the season of application of organophosphorus pesticides in the atmospheric air of towns and villages there were detected Methylmercaptophos, Rogor, Antio, and other pesticides ${ }^{2}$.

Gabor $^{3}$ cites data on the concentrations of pesticides in six settlements in the USA near which pesticides were used for the control of plant pests. DDT was found in concentrations of $0.005-0.02 \mathrm{mg} / \mathrm{m}^{3}$. In five settlements chlordan was detected in concentrations of $0.0005-0.006 \mathrm{mg} / \mathrm{m}^{3}$. In one place Aldrin and Toxaphene were detected in concentrations of 0.001 and $0.015 \mathrm{mg} / \mathrm{m}^{3}$, respectively. The author thinks that according to the estimated data, man's daily intake of DDT is about $0.0002-0.003 \mathrm{mg}$.

The analysis of atmospheric air of 11 settlements in the USA showed DDT in almost all the points and in some of them chemicals of diene synthesis and organophosphorus pesticides were found ${ }^{4}$.

Considerable concentrations of parathion (up to $0.02 \mathrm{mg} / \mathrm{m}^{3}$ ) were detected near treated gardens in the State of Washington ${ }^{5}$; in California they were up to $0.29 \mathrm{mg} / \mathrm{m}^{3}$, and in the gardens of Florida up to $0.36 \mathrm{mg} / \mathrm{m}^{36}$. There are published data ${ }^{2}$ on the content of pesticides in samples of rainwater and snow. Organochlorine pesticides in rainwater and in the snow of the UK were found in the following concentrations: DDT - up to $0.4 \mu \mathrm{g} / 1$. DDE- $0.01 \mu \mathrm{g} / 1, \mathrm{BHC}$ - up to $0.9 \mu \mathrm{g} / 1$. The source of contamination is atmospheric air ${ }^{7}$. The dispersion of chemicals widens with an increase in temperature, of wind velocity, under vertical airflows and some other conditions.

Atmospheric air is only an intermediate medium. Some proportion of the pesticides escapes; it is carried away by the wind, another part is distributed on the surfaces of plants and it forms a reserve of the active principle.

After settling down the original pesticide residues undergo quantitative and qualitative changes under the influence of environmental conditions; these result in dilution, chemical conversion and decomposition. The duration of these processes of the various chemical substances on different 
plants and under various climatic and geographical conditions ranges from several days to $2-3$ months.

Pesticides may re-enter atmospheric air from both plants and soil. From the atmospheric air pesticides may enter human organisms with inhaled air. The significance of pesticide contamination of atmospheric air in the pathology of humankind is not adequately known, but deleterious effects are quite evident.

\section{SOIL}

The ground application of pesticides results in their reaching plants and soil after passing through atmospheric air and being partially distributed in it. Later, pesticides which remain on plants also reach the soil under the influence of different, mainly microclimatic, conditions. Once on the soil, pesticides penetrate into subsurface layers; their migration velocity in soil depends on its content, and on microclimatic and other conditions. During the last twenty years a considerable amount of pesticides has entered the soil in many regions of the world.

The rate of dispersal and the time of the persistence of pesticides in soil depend on many factors among which the principal ones are the physicochemical and biological properties of soil. Organochlorine pesticides are known to be more persistent than pesticides of other chemical classes and they are detected in soil in larger quantities. The more they are used, the more they are found.

In garden soils from a few to tens of $\mathrm{mg} / \mathrm{kg}$ of pesticides are found, while in field soils only tenths of a $\mathrm{mg} / \mathrm{kg}$ can be found. Thus in the USA eight years of DDT spraying (3-4 times a year) resulted in $34.5 \mathrm{mg} / \mathrm{kg}$ of DDT in a surface soil layer (up to $15 \mathrm{~cm}$ ) under stone-fruit trees ${ }^{8}$. In one of the States of the USA $106 \mathrm{mg} / \mathrm{kg}$ of DDT was found in garden soil after eleven years of applications ${ }^{9}$.

The most persistent pesticide in soil is DDT, thus after three years of application the residual content of DDT decreased to 50 per cent, of dieldrin to 40 per cent, of heptachlor to 10 per cent, and of aldrin to 5 per cent ${ }^{10}$.

Of all the derivatives of carbaminic acid the behaviour of sevin in soil is studied most widely. This pesticide remains unchanged in the soil for 1-2 years ${ }^{11}$. The maximum quantities (a few $\mathrm{mg} / \mathrm{kg}$ ) are found in soils with good absorptive properties (chernozem); the minimal quantities (some thousandths of $\mathrm{mg} / \mathrm{kg}$ ) are found in podzolized soils with little humus content.

There are some investigations on the persistence of organophosphorus pesticides in the soil. The decomposition of Thiophos in clayey soil under field conditions is found to take place during 90 days, Carbophos and Methaphos disappear under similar condition in 8 and 30 days respectively ${ }^{12}$.

In $19690.06 \mathrm{mg} / \mathrm{kg}$ of Thiophos was detected in the depth of $0-10 \mathrm{~cm}$, $0.063 \mathrm{mg} / \mathrm{kg}$ in the depth of $10-20 \mathrm{~cm}, 0.08 \mathrm{mg} / \mathrm{kg}$ in the depth of $20-30 \mathrm{~cm}$ and traces of Thiophos in the depth of $30-40 \mathrm{~cm}$. After 16 years only one per cent of the applied quantity was found. Negligible residues of the pesticide were found in the soil of adjoining areas ${ }^{13}$.

Soil is the main cumulator of pesticides and it is the main source of secondary contamination of the components of the biosphere. Pesticides pervade 
subsoil waters and thus reach the reservoirs. From the soil some pesticides transfer into plants through their root system. When soil treatment takes place, pesticides are lifted together with soil dust into the atmospheric air and, assuredly, to working atmospheric air.

In soil, pesticides reach the organisms of all soil inhabitants, especially the soil invertebrates.

\section{WATER OF OPEN RESERVOIRS AND SUBSOIL WATERS}

Pesticides get into open reservoirs from the atmospheric air and soil with rainwater, thawed and subsoil waters.

For the control of larvae of anopheles and other insects and also for the control of aquatic weeds chemicals are applied directly into reservoirs.

In a study of river contamination of 15 watersheds in the USA in 1965 the following amounts of residues were found: DDT (hundredth-thousandths of $\mu \mathrm{g} / 1$ ), DDE (ten-hundredths of $\mu \mathrm{g} / 1$ ), Aldrin (hundredths of $\mu \mathrm{g} / 1$ ), DDE (ten-hundredths of $\mu \mathrm{g} / 1$ ), Aldrin (hundredths of $\mu \mathrm{g} / 1$ ), Dieldrin (tenthousandths of $\mu \mathrm{g} / 1$ ), Endrin (hundred-thousandths of $\mu \mathrm{g} / 1$ ), Heptachlor (traces) ${ }^{14}$.

DDT, DDE, Heptachlor and its epoxide, Endrin and Dieldrin were found in 26 drinking water samples out of $126^{15}$.

In river water in Italy traces of Lindane and Aldrin have been found ${ }^{16}$. In wells for drinking water Parathion was found at levels of hundred-thousandths of a $\mathrm{mg} / \mathbf{1}^{17}$.

Flows from agricultural fields carry into the rivers of the USA such pesticides as: DDT, Aldrin, Lindane, Toxaphene and Dieldrin ${ }^{17,18}$.

According to K. K. Vrochinsky ${ }^{19}$ in flows of thawed waters from sugar beet fields DDT was found in a concentration of about $0.01 \mu \mathrm{g} / 1$ and BHC of about $0.01 \mu \mathrm{g} / 1$; in ponds the concentrations of DDT and BHC were also up to $0.01 \mu \mathrm{g} / 1$.

In cotton-sowing regions organophosphorus compounds are found in concentrations of $0.07-0.037 \mu \mathrm{g} / 1$. in waters of subterranean horizons chlorine and organophosphorus compounds are found also in concentrations up to $0.01 \mu \mathrm{g} / 1^{20}$. In flows of rainwater when entering reservoirs the DDT concentration is about $0.00003 \mu \mathrm{g} / 1$, in fish in this case $1.0-7.4 \mathrm{mg} / \mathrm{kg}$, and in crayfish $0.5-0.7 \mathrm{mg} / \mathrm{kg}^{21}$.

Toxaphene has great migrative capacity in aquatic food chains. When the toxaphene concentration in a lake was $0.0002-0.0006 \mu \mathrm{g} / 1$, it was $0.2-$ $0.4 \mathrm{mg} / \mathrm{kg}$, in aquatic plants $0.5-1.4 \mathrm{mg} / \mathrm{kg}$ in water invertebrates, $3.5-5.7$ $\mathrm{mg} / \mathrm{kg}$ in trout and $1.8-3.24 \mathrm{mg} / \mathrm{kg}$ in salmon ${ }^{22}$. With the increase of the pesticide concentration in water larger amounts of residues are found in subsequent links of food chains. Toxaphene decomposes very slowly; in six years its content in water decreases only a few times.

Three years of applications of DDT for the control of mosquitoes resulted in the death of waterfowl, in the adipose tissue of which the pesticide was found in the quantity of $1600 \mathrm{mg} / \mathrm{kg}$, in fish the concentration was 2500 $\mathrm{mg} / \mathrm{kg}$. After 23 months from the treatment the DDT content in hydrobionta and in fowl was practically unchanged. After five years still considerable amounts of the pesticide were found. 


\section{I. MEDVED}

Fish death was observed after the Heptachlor treatment of a territory at a rate of $2.4 \mathrm{~kg} / \mathrm{ha}^{23}$. Possible cumulation of Heptachlor in fish has been established $^{23}$.

A study of the influence of Parathion on an aquatic ecosystem showed pollution of water, silt, aquatic plants (tenths of $\mu \mathrm{g} / 1$ ), fish (a few $\mathrm{mg} / \mathrm{kg}$ ), and fish death in the case of use of the pesticide for control of anopheles (application rate $1.2 \mathrm{mg} / \mathrm{kg}$ ) ${ }^{24}$

The constant arrival of pesticides in reservoirs results in storing them in fish, waterfowl, water plants and zoophytoplankton.

In most of the reservoirs and in the organisms therein different concentrations of pesticides have been found. In many countries of the world the death of fish, waterfowl and other organisms has been observed. Of all the components of the biosphere, open water reservoirs and subsoil waters hold the second place after soil as an environmental pesticide storage site.

\section{FOODSTUFFS OF PLANT AND ANIMAL ORIGIN}

In the USSR a laboratory inspection has been established for the pesticide residues in foodstuffs. More than half a million analyses are performed annually.

Prohibition of organochlorine compounds (DDT and most of the pesticides of diene synthesis) resulted in a certain purification of foodstuffs. Whereas ten years ago in 10-15 per cent of samples of foodstuffs of animal and plant origin pesticides were found in quantities exceeding hygienic norms, today such pesticide residues are found only in 3-4 per cent of the samples. And such foodstuffs are not permitted for consumption. We consider it to be our great success.

Pesticides may arrive in man's organism with foodstuffs. Attention is constantly paid to the inspection of pesticide content in food to elucidate all the sources of contamination. It is also taken into account when establishing hygienic regulations (hygienic norms, withholding periods, limiting measures of plant and animal treatment and others).

An examination of 32 kinds of assorted foodstuffs from the markets of Boston, Kansas City, and Los Angeles revealed 50 different pesticides, among them such organochlorine pesticides as: DDT, Dieldrin, Lindane, Heptachlor, Keltan, Chlordan, Pertan, and others.

Organophosphorus pesticides and derivatives of carbaminic and dithiocarbaminic acids are found in smaller quanitties.

In Holland examination of 633 samples of market vegetables and fruits revealed parathion residues in 35.7 per cent of the samples ${ }^{25}$, and in 0.3 per cent of them residue concentration was more than $1 \mathrm{mg} / \mathrm{kg}$.

In Belgium Parathion was found in apples and pears in quantities of hundredths of $\mathrm{mg} / \mathrm{kg}$.

In some countries (Italy, Hungary, Jugoslavia, Czechoslovakia and Greece) tenths and hundredths of $\mathrm{mg} / \mathrm{kg}$ of organophosphorus pesticides were found in apples, peaches, grapes, olives and other fruit.

The pesticides found in animal products may originate from the treatment of cattle and poultry, from cattle-breeding and poultry-breeding farm premises and also from contaminated feeds. Feeds, in their turn, be- 
come contaminated either directly from pesticide treatment or indirectly from pesticide drifts from adjacent treated areas, and by pesticide transfer from contaminated soil ${ }^{26}$.

In Canada 3600 foodstuff samples were investigated; in 5.9 per cent of them pesticide residues were found to exceed acceptable limits ${ }^{25}$. The most contaminated with pesticides were milk products.

In the UK butter, milk, mutton and beef tallow, and meat are contaminated with pesticides ${ }^{27}$. DDT is found in the quantities of hundred-thousandths of $\mathrm{mg} / \mathrm{kg}$, Dieldrin in tenths, hundredths and thousandths of $\mathrm{mg} / \mathrm{kg}$, Lindane in hundred-thousandths of $\mathrm{mg} / \mathrm{kg}$. High levels of DDT are found in lard and cream (tenths and a few of $\mathrm{mg} / \mathrm{kg}$ ) ${ }^{28}$.

In France Heptachlor and Dieldrin were found in 60-92 per cent of milk and milk product samples ${ }^{29}$.

A lot of data are published on DDT content in milk of cows fed with feeds contaminated with pesticides. In milk products of high fat content pesticide residues are high. High levels are found in meat, tallow, and in hen tissues and eggs.

The fact that animal products contain higher levels of pesticides than plant products shows that in circulation chains there are links which cumulate pesticides to a level greatly exceeding that of the source of contamination. The contamination sources in this case are fodder grass and fodder crops.

The problem of pesticide residues in game is especially important for those countries with widely developed hunting. The main pollutants of game are the organochlorine pesticides. In Holland DDT, Dieldrin and Endosulphan are found in the meat of European hares. Examination of reindeer and elk showed residues of DDT and DDE in 40 out of 47 samples. In some samples Aldrin and Dieldrin were also found. After forest treatment with DDT and Heptachlor these pesticides were detected in woodcock organisms: DDT at a level of $2 \mathrm{mg} / \mathrm{kg}$, and Heptachlor at levels of tenths of $\mathrm{mg} / \mathrm{kg}^{30}$. DDT is found in 100 per cent of examined eggs, Heptachlor in 30 per cent.

According to the evidence ${ }^{31}$ the treatment of a territory with Heptachlor at a rate of $2.4 \mathrm{mg} / \mathrm{kg}$ resulted in a sharp decrease in the number of grouse bred. In 15 of the bird species from 88 investigated, Heptachlor epoxide was found from a few to tenths of a $\mathrm{mg} / \mathrm{kg}$. DDT is found in the eggs of wild birds in the $\mathrm{UK}^{32}$; especially high quantities (tenths of $\mathrm{mg} / \mathrm{kg}$ ) are detected in the eggs of ouzels and pheasants. Mass death of birds is supposed to be a result of intoxication from seeds treated with Aldrin, Dieldrin, Heptachlor and organomercury compounds.

Thus pesticides are found in the environment not only in the target objects, but they permeate inevitably into some other links of the biosphere.

A considerable part of each pesticide escapes from treated areas due to the drifts, contaminating on their way new environmental objects. Subsequently each of the objects interacts with the environment and may serve as an original link of circulation in large and small ecological chains, and frequently a man may become the last link of these chains of contamination. Such original sources of contamination may be atmospheric air, water and plants.

Migration processes of pesticides from soil to the adjacent media (Atmospheric air, plants, water reservoirs) are closely connected with the capacity of 


\section{I. MEDVED}

pesticides to disperse along soil profiles. Storage of pesticides on different levels of soil leads to the contamination of various adjacent environmental objects.

During agrotechnical practices (ploughing, harrowing, fallowing, cultivation) pesticides penetrate into deeper layers of soil getting to the level of plant root systems. Moreover, agrotechnology promotes the entering of pesticides into atmospheric air in the form of vapours or with soil dust. Chemical substances accumulated in soil are absorbed by plants.

Pesticides penetrate into plants by diffusion or with soil moisture, contaminating all parts of a plant (stalks, stem leaves and fruits). The absorption of soil moisture depends on the absorptive capacity which varies from plant to plant, on soil moisture and on the quantity of atmospheric fallout.

Pesticides penetrate intensively into tuber- and root-crops, cumulating in them. Carrot, for example, has a pronounced absorptive power.

Relative to this the planting of tuber- and root-crops, especially carrot, is prohibited in the USSR on soils contaminated with persistent pesticides.

\section{CUMULATION OF PESTICIDES IN THE ORGANISMS OF MAN AND ANIMALS}

In the USSR the study of the cumulation of pesticides in man and animals has been carried out systematically during the last ten years.

In foodstuffs of animal origin various pesticides are found and this is a proof of their presence in the organisms of domestic animals and poultry. Some pesticides, especially organochlorine pesticides, are found also in different organs of wild animals.

When determining DDT in adipose tissues different quantities were found in all cases. It means that people become carriers of DDT. In people dying from cardiovascular diseases 3 and more $\mathrm{mg} / \mathrm{kg}$ of DDT were found in the heart. In many other cases no DDT was found in the heart. Experimental investigations show DDT to be a stimulator of atherosclerosis.

In many countries data are published on detecting DDT, Dieldrin and other pesticides in man.

Many scientists believe that pesticide burden in man's organism is harmful for his health. Objective experimental evidence and results of clinical observation confirm this point of view.

Pesticides are known to circulate constantly in the biosphere; they migrate from one environmental object to another remaining in each of them for some time. Regularities of their transfer from one subject to another are established.

Pesticides penetrate all links of inanimate nature and all objects of living nature.

When reservoirs are contaminated with pesticides, the latter are found in the organisms of the reservoir inhabitants. If the vegetable soil cover is contaminated with pesticides the latter are found in the organisms of birds and animals.

From the standpoint of hygiene-the science of human health-of biggest concern is the constant contamination of the biosphere - the zone where living organisms are spread. Contamination leads to a regular and 
successive concentration of pesticides in subsequent objects. For example, DDT in water of reservoirs is $0.002 \mathrm{mg} / 1$, in zoophytoplankton $-0.2 \mathrm{mg} / \mathrm{kg}$, and in fish $-2 \mathrm{mg} / \mathrm{kg}$. In soil heptachlor is $0.002 \mathrm{mg} / \mathrm{kg}$, in carrot$2 \mathrm{mg} / \mathrm{kg}$. In beet tops DDT residues are $0.02 \mathrm{mg} / \mathrm{kg}$, in hare $-2 \mathrm{mg} / \mathrm{kg}$, in wolf $-6 \mathrm{mg} / \mathrm{kg}$. Such data are widely reported.

Continuous circulation of pesticides in the biosphere may damage living beings and the health of the people.

To prevent or decrease danger sharply it is necessary:

(1) To pay special attention to the selection of pesticides. Not to permit introduction of persistent pesticides able to accumulate in living organisms. In the USSR use of DDT has been prohibited in cattle-breeding from 1962 and in plant-breeding from 1970. Aldrin, Dieldrin, and other compounds of diene synthesis are prohibited. Efforts of the synthetic chemists are focused on the development of safe or less dangerous pesticides.

(2) To concentrate efforts on setting up more strict hygienic regulations of pesticides use. Their forms and application methods should ensure minimal escape of pesticides to atmospheric air and open reservoirs.

Withholding periods must guarantee purity of plant products.

In the USSR hygienic norms of pesticide residues in foodstuffs, in water reservoir, in atmospheric air and in soil have been worked out.

By protecting the most important objects of the biosphere from excessive contamination, we protect people's health and the life of present and future generations.

\section{REFERENCES}

1 V. I. Vernadsky. The Selected Works, V.I.: Moscow (1954).

${ }^{2}$ G. A. Belonozhko and Yu. A. Kuchak, in Hygiene and Toxicology of Pesticides, Issue 9, Kiev (1971).

3 E. Gabor, J. Air Pollut. Contr. Ass. (1965).

${ }^{4}$ H. Finkelstein. Public Health Service US, 53 (1965).

${ }^{5}$ K. Walker et al. J. Agr. Food. Chem. 2, 1034 (1954).

American Cyanamid Company, New York (1951).

7 D. Abbot et al. Nature, London, 208. No. 5017, 1317 (1965).

${ }^{8}$ G. Ginsburg et al. J. Econ. Ent. 47, 457 (1954).

9 X. Fleming and W. Maines, J. Econ. Ent. 47, 165 (1954).

${ }^{10}$ E. Lichtenstein, J. Agr. Food Chem. 7, 430 (1959).

11 E. G. Molozhanova. Sevin Circulation in the Environment. Auto-report: Kiev (1970).

12 H. Maier-Bode, Pflanzschutzmittel Rückstände. Stuttgart (1965).

13 D. Stewart, Nature, London, 229, No. 5279, 49 (1971).

14 L. Weaver et al. Public Health Report, 80, 6 (1965).

15 F. Taylor, J. New Engl. Water Works Ass. 79, 3 (1965).

${ }^{16}$ F. Petrilli et al. J. Igiene Prev. 8, 3 (1967).

${ }^{17}$ H. Nicholson, W.P.A. (1966).

18 S. Faust, J. Amer. Med. Ass. 56, 267 (1964).

19 K. K. Vrochinsky, in Hygiene and Toxicology of Pesticides. Kiev (1967).

20 A. L. Rudackov et al., in Works of Scientific-Practical Conference of Kirgiz SRI of Epidemiology, Microbiology and Hygiene. Vol. 10. Frunze (1969).

21 S. Hopkins et al. N.Z.I. Sci. 9, 236 (1966).

22 Z. C. Terriere et al. J. Agr. Food. Chem. 14, I (1966).

23 C. Hoffman, J. Agr. Chem. 7, 41 (1954).

24 S. Mulla Mir, J. Econ. Ent. 59, 5 (1966).

25 H. Hardon, Verhande IV Int. Pflanzenschutz Kongress. Hamburg (8-15 September 1957). 


\section{I. MEDVED}

${ }^{26}$ F. Beran. Pflanzenschutz Berichte. Wien. 27.11 (1961).

27 P. Cornwell, Brit. Food J. and Hyg. Rev. 66, 787 (1964).

28 G. Zigeti, B. Ciszar and L. Mindszenty. Die Nahrung, 4 (1967).

29 G. Thienlin et al. Bull Acad. Nat. Med. (1966).

30 W. Bruce, J. Wildife Manag. 29, 1 (1965).

31 W. Rosene, J. Wildlife Manag. 29, 3 (1965).

31 A. Taylor, J. Bird Study, 11, 192 (1964). 